European Journal of Pragmatism and American Philosophy

VII-2 | 2015

John Dewey's Lectures in Social and Political Philosophy (China)

\title{
Chance and Regularities
}

Remarks on Richard Rorty's Contingentism

Rosa M. Calcaterra

\section{CpenEdition}

\section{Journals}

Electronic version

URL: http://journals.openedition.org/ejpap/417

DOI: 10.4000/ejpap.417

ISSN: 2036-4091

\section{Publisher}

Associazione Pragma

\section{Electronic reference}

Rosa M. Calcaterra, "Chance and Regularities », European Journal of Pragmatism and American

Philosophy [Online], VII-2 | 2015, Online since 23 December 2015, connection on 21 April 2019. URL

http://journals.openedition.org/ejpap/417 ; DOI : 10.4000/ejpap.417

This text was automatically generated on 21 April 2019.

\section{(i) $\Theta \Theta$}

Author retains copyright and grants the European Journal of Pragmatism and American Philosophy right of first publication with the work simultaneously licensed under a Creative Commons AttributionNonCommercial-NoDerivatives 4.0 International License. 


\title{
Chance and Regularities
}

\author{
Remarks on Richard Rorty's Contingentism
}

\author{
Rosa M. Calcaterra
}

1 When accounting for human events, biographical paths, the life of nature in which we are immersed, and even cosmic reality, common sense and ordinary communicative practices deploy regularity and chance as either opposing terms or, alternatively, as an inseparable conceptual couple. These two possibilities, which often feature in the same discursive context, sometimes in alternation, or even coexist rather than exclude themselves from each other, eventually reveal our deep unease with handling unequivocal, neutral, or "objective" categories - like those of regularity and chance - which animate the development of our culture from within. An intricate web of logical and semantic criteria, in addition to psychological and anthropological implications, holds together these two concepts according to very complex interactions. However, for purposes of simplification, their different treatment in our philosophical tradition can be seen in two canonical fronts: chance, or, in more current terms, contingency, and necessity or determinism.

2 It is easy to observe that the first theoretical aspect is one of the most consolidated approaches in postmodernism. I would like to briefly show how the metaphysical quality of the question of the relationship between regularity and chance flows into the construction of postmodern discourse, although in a very different way, and, indeed, under the auspices of the anti-metaphysics that such a discourse claims. I borrow the term "tychism," which names Peirce's cosmological-metaphysical theory of chance, because I think it lends itself to a translation on the level of postmodern philosophy, in particular to a positive reading of the connection between history and chance that stands out in the work of Richard Rorty, the 'post-modern' neo-pragmatist philosopher par excellence. Despite Rorty's decision to write off the philosophy of Peirce from his list of sources of inspiration, I believe that the tychism that appears in the latter as an integral part of the ontological framework of a semiotic epistemology centered on fallibilism and the so-called "logical socialism" offers ideas that must be re-evaluated in relation to the ethical stance that goes with Rorty's anti-foundationalism. 
3 As mentioned above, contingentism has received widespread support within postmodern culture. More precisely, a good part of the various criticisms of modernity provided in contemporary culture converge in the tendency to nourish a serious suspicion regarding any attempt to trace back human phenomena to a deterministic framework, that is a metaphysical perspective according to which all realities imply an intrinsic teleology. Such a framework à la Wolff would in principle rule out chance as an effective component working in each order of reality, or reduce it to a mere accident of pre-determined substance of being. On the other hand, the biology of the twentieth century provided an ever wider currency to the idea that chance intervenes at various levels of life in nature or, rather, that it is a determining factor of every novelty in the biosphere. In this respect, the biological studies of Jacques Monod are paradigmatic. However, it is important to notice his assertion that the emergence of ethical and moral issues and, more generally, ideas of value within the evolution of reality, mark the "frontières de l'inconnu" (Monod 1970: 156).

4 As a matter of fact, the fascinating theme of the relationship between the chance and the regularity of phenomena of both the physical-material and the historical-social world runs through, in a more or less declared way, scientific and philosophical research. Furthermore, it would be incongruous and misleading to downplay the psychological and existential implications that such a problem entails. In fact, the idea of chance acts mostly as a disturbing challenge to our need for security that certainly the idea of regularity succeeds somehow to fulfill. But the reverse question is also worth inquiring: to emphasize regularity, in an extreme analysis, leads to closing the space of freedom and of human responsibility, while the notion of chance offers, at least in principle, the possibility that the events that mostly concern humans do not form a mechanical chain so strong that can never be broken - or, alternatively, chance can be thought of as one of the names we give to what seems imponderable to us in the present moment.

5 This ambiguity, which could be defined at first as a psychological and existential ambiguity, is reflected at the logical and semantic level and, in any case, has extremely concrete roots. In fact, regularity presents itself in an objectively observable way, so as to be/become the very raison d'être of our scientific and philosophical efforts to obtain explicative and, at the same time, predictive, theories of the development of physicalmaterial and cultural facts. The regularities of the relations between phenomena "appeal to our intelligence as its cousins," wrote Peirce (CP 6.64), while the concept of chance is itself "unintelligible" ( $\mathrm{CP}$ 6.52), that is it does not explain anything. Yet, it bursts powerfully onto the stage of scientific research whenever one realizes that the analysis of "facts" not only fails to produce any explanation of the irregularities that are revealed during their investigations, but also fails to declare, on the simple basis of their logical and empirical means, the causes to assign the onset of regularities that support the observed phenomena (Peirce 1923: 201).

It is important to note that Peirce associates the category of chance with the notion of the "spontaneity of nature" and, in parallel, with the category of law/regularity. His suggestion is to consider the hypothesis that chance/spontaneity constitutes a component of the life of the Universe that is not in opposition to the idea that the universe is governed by the principle of necessity or objective legality. The metaphysical conjecture of chance could rather offer an answer to the difficulties about determinism raised by evolutionary theories. Therefore, Peirce holds that chance/spontaneity implies a certain degree of regularity, which in fact gets manifested in the evolutionary continuity, 
that is to say, in the increasing complexity of reality, which is marked by the diversification of nature. The latter is considered as an intrinsic moment in the becoming of nature, and not as its original cause: the principle of chance cannot be invoked to explain either natural facts or their variations.

Peirce was well aware that the establishment of the intertwining of chance/spontaneity and regularity/legality of nature was not sufficient to respond to questions concerning the relations between "psychic" and "physical" facts. To be sure, these questions ultimately imply the possibility of explaining the position of human beings in the evolutionary reality of the universe and, in the end, of giving an account of the relationship between nature and culture. Peirce's synechism, his theory of logicalontological continuum, aimed at providing the epistemological tools to address precisely these questions. However the deep union of liberty/spontaneity and necessity/law is, for Peirce, only a working hypothesis, and actually represents an "open question" - as he says in "The Architecture of Theories." In this article, he tries to sustain that regularity makes action by chance/spontaneity effective, since it constitutes the moment in which the causal event turns into a new "fact" that fits into the preexisting natural context. Apart from the difficulty that Peirce's cosmology certainly involves, what appears particularly interesting is the connection between chance/spontaneity and regularity/ law that forms the evolutionary continuum, which in fact excludes an absolute original causal principle. After all, this connection corresponds, for Peirce, to the hypothesis that accounts for one of the cornerstones of his thought, namely fallibilism. To such an insurmountable normative criterion of his philosophy Peirce entrusts the authentic spirit of scientific research, and more specifically both its epistemic and ethical peculiar quality. "The principle of continuity is the idea of fallibilism objectified" (CP 1.171) he declares, and in his prospect of his planned The Principles of Philosophy, he specifies: "The great opponent of this philosophy has been in history, and is in logic, infallibilism, whether in its milder ecclesiastical form, or in its more dire scientistic and materialistic apparitions" (CP 8, 284, c.1893).

The scientific-philosophical problem of the relationship between regularity and chance inevitably, although subliminally, verges on the metaphysical level of analysis. Therefore it is opportune to reflect on the use of such concepts in order to improve our awareness of the logical and semantic depth of the words that weave our discourse. From a theoretical point of view, the most critical issue is asking if and to what extent it is legitimate to treat the notions of regularity and chance in terms of absolute original principles of phenomenical reality. A positive answer would mean accepting to treat these notions according to the traditional foundationalism's necessity to indicate a selfsufficient ontological and gnoseological primum, which could serve as a sort of Archimedean point on which to base all our knowledge and value statements. As noted above, Peirce's tychism can be read as a step toward overcoming such a perspective. In any event, the postmodern culture, together with kindred pragmatism-inspired philosophies, surely promotes the rejection of the idea of the absolute primum, committing rather to the elaboration of philosophical alternatives to the traditional foundationalist stance through which the very idea of "foundation" is re-structured according to a pragmatic meaning. In a few words, this means to bypass traditional both empiricist and rationalist foundationalism focusing, rather, on the continuous interference of conceptual and empirical factors in all forms of human intelligence and, therefore, on individual and social action as a criterion of fundamental importance and 
yet disengaged from any absoluteness. Thus agency is conceived as the result of an interpretation of the plot between the logical-semantic elements and the empirical elements that compose the development of the human world. To put it differently, action is a "fact" (pragma) relative to an interpretative context that, in principle, bids fallibility instead of indisputability, and the possibility of adjustment and even of substantial transformation instead of definitive certainty. ${ }^{1}$

9 According to this view, one can see a fruitful ethical harmony between Rorty's steadfast battle against foundationalist epistemologies, ${ }^{2}$ on the one hand, and the centrality of the theme of cultural differences in postmodern thinking as oriented towards contingency, on the other hand. As is known, the affirmation of the necessity to not simply recognize differences but above all respect them and treat them as sustenance for the construction of individual and social life has involved, in a broad way, various areas of artistic and philosophical production, and has been realized through more or less radical deconstructions of a large portion of the vocabulary of modernity. Both on the theoretical and ethical-political levels, all this has seriously undermined modern thinkers' attitude to construct abstract philosophical models. In particular, one can notice attacks on two closely interconnected demands in modern philosophical thought: the a-temporal or essentialist images of so-called human nature and the subsequent effort to reduce the disparity of intellectual and social practices through the formulation of abstract principles or purposes of rationality. The continuous remarks of Rorty on both matters ${ }^{3}$ fruitfully intersect with the harsh criticisms that Jean-François Lyotard - an emblematic representative of postmodern thought - pushed forward in confronting the incapacity of philosophical thought to recognize the fluidity of knowledge and practice. In a nutshell, Lyotard challenged modern philosophers for being unable to acknowledge the ever flowing equilibrium that human inventiveness can set into motion to respond to the problems and expectations that gradually emerge in each historical and social contexts. ${ }^{4}$ It is precisely because of such a philosophical myopia that, according to Lyotard, the crisis of the "métarécits" offered by the great thinkers of modernity has occurred and reached a point of no return. According to his analysis, all systematic modern philosophies produced these meta-narratives just to try for a unitary - basically teleological and necessary - justification of the developing processes of the western world.

Lyotard's expression métarécits is established as one of the most influential metaphors within contemporary debate regarding the notions of human nature and rationality based on the epistemological criteria shaping up the plot of philosophical systems of modernity. It would be interesting to see exactly to what extent the main lines of thought of this leading figure of the 'philosophie de la différence' closely dovetails with the formulation, "One world, but one world in paribus," in which the sociologist Horace M. Kallen synthesizes the principle of 'cultural pluralism.' However, I limit myself to note the pervasiveness of the latter expression in the current language of western society, where in fact its recurrence is now consolidated in the most oddly assorted theoretical or media contexts. In any event, from a broader point of view, one can glimpse a significant agreement between the philosophies of Rorty and Lyotard regarding Kallen's clarification that the expression 'cultural pluralism' designates a precise socio-political orientation according to which one hopes for a human world enriched by the contributions of its local diversities. But it is evident that such a socio-political orientation entails specific theoretical and ethical orientations. 
11 There is an evident asymmetry between the convincing discourses provided for supporting the principle of cultural pluralism and the concrete dynamics of the socioethical reality of our time. Nevertheless, one must consider if such a discrepancy may justify bracketing or even eliminating postmodern critiques on the traditional search of all-encompassing epistemic and practical criteria. These critiques, in fact, intertwine with an appeal to adopt a pluralist perspective focused on the respect for, and the appreciation of, both synchronic and diachronic differences that mark the human world. One can try to understand this aspect of the controversies about modernity in the light of the Kantian notion of "regulative ideal," which hinges precisely upon the recognition of the normative potential yet to be fully realized in our ideas of truth and value. It is an aspect of Kant's thought that, in my view, condenses his discovery of the solid practical function of human attitude to ideality. Although it may seem paradoxical, since he is a prominent protagonist of modernity, one can see that Kant's concept of "regulative ideal" tacitly plays an important role also in the pragmatist postmodernism of Rorty. First of all, this concept seems implied in the emphasis that he laid upon the 'prophetic' quality of philosophical discourse and, more generally, in the most characteristic features of his historical anti-foundationalism.

Before addressing more closely these elements in the work of Rorty, one should acknowledge that postmodernism and neo-pragmatism certainly present noteworthy 'family resemblances,' in the sense of Wittgenstein's famous expression. Nonetheless, and following precisely Wittgenstein's suggestion, to draw up a list of their affinities would be a very complex and, also, rather risky endeavor. ${ }^{5}$ This is due to the simple fact that neither of these two terms - postmodernism and neo-pragmatism - can designate a compact and unequivocal cultural movement. Like all labels, 'post-modernism' and 'neopragmatism' serve to gather under a single tag a complex variety of starting points, styles and perspectives that are both theoretical and socio-political. ${ }^{6}$ However, apart from their internal diversity, both classical and contemporary pragmatist philosophers share with postmodernism a particular attention to the value of human practices, historicity, and dynamism of epistemic and value criteria. In short, there is a fully shared commitment to show the interpretive and constructing mark of human intelligence or, as William James said, to show that "the trail of the human serpent is thus over everything" (James 1975: 37).

13 Richard Rorty gave voice to this philosophical attitude with particular vigor. It is fundamental to consider that he intentionally adopted a provocative style to bring forward his project to form a cultural climate in which one would be able to renounce a number of theoretical and methodological criteria deeply rooted in the western philosophical tradition. It would be a cultural climate in which, first of all, one would be able to reject the essentialist mindset, which marks the origins and developments of our history of ideas. It is precisely at this level that Rorty's 'post-philosophy' amounts to a serious attack against any kind of dogmatism, whether epistemic, value-related, or sociopolitical: an attack launched along with an insistent call to recognize the radical contingency of our ways to know, evaluate, and even plan our future, but such a call holds a deep ethical tonality.

14 The combination of contingency/chance and ethical intention certainly poses problems. Any ethical proposal involves the idea of some norms to be implemented, which, in turn, implies the issue of individual or social approval, that is, the idea of the responsibility of the agents to implement or not a certain normative settings. But then, how can one 
conciliate all of this with Rorty's emphasis on the radically contingent nature of all our cognitive and behavioral criteria, an emphasis that risks to dissolve irreparably the very notions of normativity and responsibility? Yet, one might say that the typically postmodern challenge of constructing a pluralistic mentality against any form of authoritarianism - a challenge which is particularly evident in Rorty's philosophy - just takes advantage of the tension between contingency and ethics, instead of simply outlive it. In this regard, it is particularly interesting to consider the semantic and conceptual coupling between contingency/chance and history, which bakes up Rorty's assertion that there are no ethical certainties or epistemic truths guaranteed once and for all as well as his proposal of an ethical commitment that would concern each and every one of us.

One can easily observe, in fact, that chance is most invoked simultaneously with the statement of historicity of all human events and phenomena. Nevertheless, in various argumentative contexts, one notes a subtle yet constant shift between the meaning of chance as a merely fortuitous causal power of historical evolutions and as an opportunity or a potentiality that is offered to human initiative, although always under the sign of its radical finiteness and fallibility. Some vital aspects of Rorty's philosophy fall into the latter category, aspects that would otherwise remain completely meaningless or even trivial enough to border on mere rhetorical fiction. It is precisely in this light that ethical normativity can be recovered within Rorty's contingentism. I am thinking in particular to irony as a pivotal aspect of his ethical-political prospective, which elsewhere I define as "aesthetic meliorism" and, more specifically, to his assertion that "there is such a thing as moral progress, and that this progress is indeed in the direction of greater human solidarity" (Rorty 1989: 192).

To be sure, this assertion might seem at first glance quite discordant with the many phenomena of lack of solidarity that each of us can list from our own personal experiences as well as those from the international socio-political situation. Nevertheless, it would be inappropriate to get rid sic et simpliciter of Rorty's assertion that the value of solidarity has gradually strengthened enough to have a major or central role in the positive evolution of the moral field. One can observe, in fact, that there has been an always-growing number of initiatives based on the criterion of solidarity, which acquired various forms of institutionalization. Apart from some undeniable critical points of the neo-pragmatist contingentism of Rorty, it is worth to notice of the crucial connection of communicating, feeling, and doing that such a philosophical viewpoint recommends as an alternative to traditional philosophical accounts of human solidarity.

17 To briefly illustrate this suggestion, one must recall the heuristic function that the theme of hope unfolds in the cultural project of Rorty. Placing himself on the same wavelength as the founding fathers of American democracy as well as Ralph Waldo Emerson, Walt Whitman, and John Dewey, Rorty's philosophical discourse seeks to support "the ability to believe that the future will be unspecifiably different from, and unspecifiably freer than, the past" (Rorty 1999: 120) that, according to him, characterizes the original spirit of American democratic culture. Thus he may be included among the 'classical' representatives of meliorism that characterizes the American cultural tradition, of which he certainly tends to increase the 'aesthetic' dimension, that is to say, those lines of thought that privilege the function of sentiments with respect to other dimensions of the human being. Such a meliorist-aesthetic orientation is precisely specified in Rorty's appeal to revive hope in a continuous increase in sentiments of human solidarity and of their unique ability to face oppression and cruelty, relying not on rationalist stances but 
rather on the power of imagination and on literary narratives. Such a hope rests on the abandonment of the rhetoric of objectivity to try to bring forward instead the possibility of realizing in acceptable terms the search for individual autonomy from transcendent forces and principles, or better, the search for self-reliance, which modernity itself had presented as in apparent contrast with its foundational demands of epistemic extratemporal principles and morals. To make a very general note, think of the theories of sovereignty of the self that, starting with Descartes, extend throughout the whole modern era, finding an exemplary stage in the Kantian theory of the dynamic connection between autonomy of reason, liberty, and moral obligation. ${ }^{8}$

Although all this paved the way for the process of disengagement of the value of solidarity from theological vocabulary and essentialist theories of the human subject, thus favoring the processes of democratization, according to Rorty the crucial point in modern thought lies in its having obfuscated the importance of the empirical approach to the sphere of moral values. On the contrary, his contingentism forces philosophical attention to the empirical components of ethical and moral criteria, suggesting tacitly that it is only from this point of view that one can speak of moral obligation without succumbing to mere precepts, whether of the philosophical or theological type. Indeed, on this issue Rorty's position serves to radicalize the classical scheme for which there can be no moral responsibility if there is no freedom to choose. That is, as Rorty himself affirms, "Moral obligation is, in this view, to be thrown in with a lot of other considerations, rather than automatically trump them" (Rorty 1989: 194). Furthermore, speaking of ethical and moral empirical criteria is in line with the primary commitment of his philosophical project: namely, that of rejecting any non- or extra-discursive constrains on our inquiry, whether scientific or ethical-political, that is the commitment to argumentation and justification proposed in the course of inquiry alone. ${ }^{9}$ However, this amounts precisely to the assertion of a normative criterion to implement or, better, an ideal to render regular.

19 Let us return to the declaration that "there is such a thing as moral progress," for which it is necessary to recall a decisive component of Rorty's thought: human history is linguistic history, that is to say, it amounts to the evolution of "vocabularies" corresponding to the various forms of life gradually articulated in and by them. Above all, it is a history marked by influential metaphors in which instances of change in human life, as well as re-descriptions of the very natural and social reality in which we are immersed, reverberate. In sharp disagreement with the universalist repertoire of modern philosophy, Rorty underscores the linguistic nature of every human activity, or better, the symbolically mediated feature of the very logical-cognitive parameters that, govern our living practices just as our personal and cultural identity. In this framework, drawn on the philosophies of Wittgenstein and Davidson, Rorty supports a notion of the self as centered on contingency rather than on essentialism, contributing therefore to a narrative model of personal identity, according to which it consists of a process of selfdescription where each of us puts in place a request of recognition by others. This is a process that establishes a strong connection between language, social interaction, and selfawareness, posing the creation and acquisition of new metaphors, and in the end, of new vocabularies and ways of speaking, like the strengths of ethical development of society.

As a consequence, Rorty invites us to pursue what he retains should be an important factor of contemporary feminism, that is, the "ability to eschew such Enlightenment fantasies of escape," without, however, succumbing to the seductions of relativistic or 
irrational rhetoric of postmodernism or to the dynamic of effective powers. More precisely, the invitation is to avoid "the embarrassments of the universalist claim that the term human being - or even the term woman - names an unchanging essence, an ahistorical natural kind with a permanent set of intrinsic factors," therefore leaving behind "questions about the accuracy of their representations of "woman's experience'." Alternatively, women would themselves be "creating such an experience by creating a language, a tradition, and an identity" (Rorty 1992: 15).

This approach to the issues of feminism is a specific application of what might be defined as Rorty's 'linguistic historicism.' The latter includes among its central notions that one of "semantic authority," according to which one can acquire a moral and social identity only when one is able to regain the space of one's "public word" and, above all, to the extent that one's discourse is starting to have success, that is it is recognized and attended by other people. It is therefore necessary to prepare the means, not yet currently available, that would help individuals and social groups suffering from marginalization and injustice to define themselves, their own purposes and needs. It is precisely here where one finds the gap between pragmatism and the universalist paradigm that _- according to Rorty _- is equivalent to both ethical and epistemic realism, which, in turn, often coincides with necessitarianism. Alternatively, this requires the recovery of the aesthetic dimension in which, as mentioned above, Rorty couches the key notion of his philosophical proposal: the sentiment of solidarity.

It is strange that among those authors particularly sensitive to the aesthetic level of culture, and therefore to its importance for philosophical reflection, some are indeed very critical of Rorty's thought. A significant example seems to be that of Thomas Alexander, who holds that human beings strive to live concrete experiences of meaning and value, especially those embodied in the world. In brief, according to his theory, being a primary biological necessity, the need for meaning and value is so radical that its exclusion inevitably brings either death or destructive fury, being. ${ }^{10}$ Alexander does not hesitate to define this as Eros, a term that, in his language, indicates a "desire or need" rather than an exercise in human will: "We need to feel that our own lives are meaningful and have value" (Alexander 2013: 6). Therefore, he poses an intimate link between the fields of biology, aesthetics, meaning, and value, and it is precisely on this intersection that the important recovery of the philosophy of John Dewey on the part of Alexander insists. In the end, he attributes to Dewey the merit of having constructed on solid philosophical bases an "ethics of meaning," while Rorty would have turned pragmatism in an extreme form of irrationalism and moral relativism. ${ }^{11}$ In truth, Rorty repeatedly rejected this charge, and one can instead say that he has re-proposed, with new and more refined philosophical tools, the great challenge launched by the classical pragmatists, especially by James and Dewey: to translate the pathos of contingency into an ethos that is able to combine the dismissal of absolutes with the responsibility to construct meanings and values, accepting the argumentative interpersonal and intercultural practices as the regularity of our moral history. 


\section{BIBLIOGRAPHY}

ALEXANDeR T., (2013), The Human Eros. Eco-ontology and the Aesthetics of Existence, New York, Fordham University Press.

CALCATERRA R., (2003), Pragmatismo: i valori dell'esperienza, Roma, Carocci.

CAlcaterra R., (2008), "Truth in Progress The Value of the Facts-and-Feelings Connection in William James," in M. C. Flamm, J. Lacks, \& K. Skowronski, eds., American and European Values: Contemporary Philosophical Perspectives, Newcastle upon Tyne, Cambridge Scholars Press, 90-105.

CAlCATERRA R., (2014), “The Linguistic World. Rorty's Aesthetic Meliorism,” in L. Koczanowicz, ed., Beauty, Responsibility, and Politics. Ethical and Political Consequences of Pragmatist Aesthetics, New York-Amsterdam, Rodopi.

FRANKL V., (1948), Man's Search for Meaning, New York, Simon \& Schuster.

JAMES W., (1975), Pragmatism, Cambridge Massachusetts, Harvard University Press.

MALACHOWSKI A., (2010), The New Pragmatism, Durham, Acumen.

MONOD J., (1970), Le hasard et la nécessité. Essai sur la philosophie naturelle de la biologie moderne, Paris, Éditions du Seuil.

PEIRCE C. S., (1923), Chance, Love, and Logic: Philosophical Essays, London, Kegan Paul, Trench, Trubner \& Co.

PIPPIN R. B., (1991), Modernism as a Philosophical Problem: On the Dissatisfactions of European High Culture, Oxford, Basil Blackwell.

RORTY R., (1979), Philosophy and the Mirror of Nature, Princeton (NJ), Princeton University Press. RORTY R., (1982), Consequences of Pragmatism, Minneapolis, University of Minnesota Press. RORTY R., (1984), “Habermas and Lyotard on Postmodernity,” Praxis International 4, 32-44. RORTY R., (1989), Contingency, Irony, Solidarity, Cambridge (MA), Cambridge University Press. RORTY R., (1992), “Feminism and Pragmatism,” The Tanner Lectures on Human Values, vol. 13, Salt Lake City, University of Utah Press, 1-35.

RORTY R., (1999), "Education as Socialization and as Individualization," in R. Rorty, Philosophy and Social Hope, Penguin UK.

\section{NOTES}

1. For a more detailed discussion of these aspects, see Calcaterra 2003.

2. The most decisive arguments in this regard can be found in Rorty 1979.

3. For the anti-essentialist theory of human nature, see in particular Rorty (1989: 35-56).

4. The continuities and discrepancies between Rorty and Lyotard are documented in Rorty 1984.

5. An attempt of this type is in Malachowski (2010: 6-16). 
6. Regarding neo-pragmatism, one can even note a consistent tendency to distinguish it from 'new pragmatism,' meaning, in the case of the latter term, a movement toward the revision of Rorty's thought. After all, ever since its birth, pragmatism has been marked by a variety of aspects and directions, a variety that nevertheless represents different ways of declining a common project, rather than true and real speculative contrasts. I have argued this thesis in various contexts, among which I recall Calcaterra 2003, and Calcaterra 2008.

7. See Calcaterra 2014.

8. An interesting clarification of the centrality of the issue of subjective autonomy in modern thought can be found in Pippin 1991.

9. See Rorty 1982.

10. See Alexander (2013: 6). In support of the thesis of the biological nature of the need for meaning and value, the author invokes the famous work of the psychiatrist Viktor Frankl (see, Frankl 1948), which shows the experience of prisoners in Nazi concentration camps who that the search for meaning constitutes a "primary motivational force" of human life and not an already "secondary rationalization" of instinctual drives.

11. See Alexander (2013: 142-58).

\section{ABSTRACTS}

The relationship between regularity and chance, or necessity and contingency, is a common concern of classical pragmatists. The metaphysical quality of this issue flows into the construction of postmodern discourse, although in a very different framework and, paradoxically, under the auspices of the anti-metaphysics that such a discourse claims. This paper proposes at first a brief reconstruction of the chance and regularity issue in postmodernism; then Peirce's cosmological-metaphysical theory of chance, namely his 'tychism,' is recalled as a fruitful suggestion to avoid the conceptual split between chance and regularity. Subsequently, considering the family resemblances between postmodernism and Rorty's neopragmatism, the insistence upon history and contingency that stands out in his work will be tackled as a 'postmodern tychism' that, in fact, does not fit too-easy readings according to which he would have turned pragmatism into an extreme form of irrationalism and radical moral relativism. In particular, this paper aims to enlighten Rorty's effort to re-propose, with new and more refined philosophical tools, the great challenge posed by the classical pragmatists: namely, the challenge to translate the pathos of contingency into an anti-dogmatic ethos, that is a cultural stance that might be able to combine the rejection of absolutes with the commitment to construct meanings and values hosting argumentative interpersonal and intercultural practices as the 'rule' of our moral history.

\section{AUTHOR}

\section{ROSA M. CALCATERRA}

Università Roma Tre

rosamaria.calcaterra[at]uniroma3.it 